\title{
The Relationship of Positive Affect with Resilience and Self-Efficacy in Life Skills in Italian Adolescents
}

\author{
Elisabetta Sagone, Maria Luisa Indiana \\ Department of Educational Sciences, University of Catania, Catania, Italy \\ Email: esagone@unict.it, mluisa.indiana@gmail.com
}

How to cite this paper: Sagone, E., \& Indiana, M. L. (2017). The Relationship of Positive Affect with Resilience and Self-Efficacy in Life Skills in Italian Adolescents. Psychology, 8, 2226-2239. https://doi.org/10.4236/psych.2017.813142

Received: September 8, 2017

Accepted: November 27, 2017

Published: November 30, 2017

Copyright $\odot 2017$ by authors and Scientific Research Publishing Inc. This work is licensed under the Creative Commons Attribution International License (CC BY 4.0).

http://creativecommons.org/licenses/by/4.0/

\section{(c) (i) Open Access}

\begin{abstract}
The main purpose of this study was to analyze the relationships of positive affect with dimensions of resilience and perceived self-efficacy in life skills in a sample of 147 Italian healthy adolescents. We used the Positive and Negative Affect Schedule (PANAS), the Resiliency Attitudes and Skills Profile (RASP), and the Perceived Self-Efficacy Scales in Life Skills. Statistical analyses indicated that adolescents with high positive affect reported higher levels of perceived self-efficacy in life skills than those with low positive affect; in addition, adolescents with high positive affect reached higher levels of resilience (that is, adaptability and engagement) than those with low positive affect. Given the relationship of positive affect both with dimensions of resilience and perceived self-efficacy in life skills, future investigations could better understand the functioning of protective factors actively engaged in facing up to the transition from childhood to adolescence, in line with the flourishing approach in supporting the promotion of psychological well-being and the increasing of individual's bio-psycho-social skills.
\end{abstract}

\section{Keywords}

Resilience, Positive Affect, Self-Efficacy, Life Skills, Italian Adolescents

\section{Introduction}

The main purpose of this paper was to study how positive affect can be in relation to the dimensions of resilience and perceived self-efficacy in life skills during the period of adolescence. As reported by the Watson and his colleagues' perspective (Watson et al., 1988), positive affect (PA) corresponds to the extent to which an individual feels enthusiastic, active, and alert, while negative affect 
(NA) reflects subjective distress and unpleasurable engagement that generate a broad range of aversive mood states, including anger, disgust, guilt, and fear. Individuals who experienced high levels of PA are characterized by high energy, full concentration, and pleasurable engagement, whereas those who experienced low levels of PA are characterized by sadness and lethargy. Watson \& Tellegen (1985), as well as Tellegen, Watson, \& Clark (1999), found that these two dimensions are independent: the increased levels of positive affect are not related with the decreased levels of the negative one. However, Norlander, Johansson, \& Bood (2005), as well as Archer, Adolfsson, \& Karlsson (2008), considered positive and negative affect as parts of an affective profile model articulated into four different types: 1) "self-fulfilling profile", characterized by high levels of PA and low levels of NA; 2) "high affective profile", given by high levels of PA and high levels of NA; 3) "low affective profile", formed by low levels of PA and low levels of NA; and, finally 4) "self-destructive profile", given by low levels of PA and high levels of NA. Several researches investigated the relationship between the affective profiles and different psychological constructs (e.g., life satisfaction, psychological well-being, optimism, locus of control) and suggested that individuals with self-fulfilling profile were more satisfied, optimistic, and autonomous than the others (Garcia \& Siddiqui, 2009; Garcia, 2012), also revealing higher levels of psychological well-being, self-esteem and internal locus of control than individuals with self-destructive profile (Archer et al., 2008). Additionally, on the basis of the revisited Ryff's eudaimonic perspective (Ryff, 2014), Garcia \& Moradi (2013) compared the affective profiles of Swedish adolescents with those of Iranian ones, underlining that all adolescents with self-fulfilling profile showed higher levels of life satisfaction and psychological well-being than the others, without significant differences for nationality. In Italian context, Di Fabio \& Bucci (2015) analyzed the differences among the affective profiles of Italian students in relation with life satisfaction and psychological well-being, noticing that students with self-fulfilling profile had greater life satisfaction and psychological well-being than those with high affective, low affective and self-destructive profiles; in addition, they analyzed the differences among affective profiles in relation with optimism and self-esteem, showing that students with self-fulfilling profile obtained higher scores on optimism and self-esteem than those with the other affective profiles. In another recent study, Garcia et al. (2017) examined differences in subjective well-being and psychological well-being between Swedish and Italian adolescents and investigated if the relationships between the three constructs of subjective well-being (life satisfaction, positive affect and negative affect) and psychological well-being were influenced by the adolescents' nationality. The results showed that life satisfaction was higher in Italian adolescents compared to Swedish adolescents: life satisfaction was more strongly related to psychological well-being among Swedish adolescents. Finally, in both countries, no significant differences in the relationship between the three constructs of subjective well-being and psychological 
well-being were found.

With reference to the link between positive affect and resilience, scientific literature provided a considerable amount of definitions relating to this construct. So, resilience can be defined as a result characterized by functional behavior models despite situations of risk, and, alternatively, as a dynamic process of adaptation of a person to an adverse situation that involves the interaction between risk and protective factors of the individual related to social situations (see Luthar \& Cicchetti, 2000). In addition, it was defined by Wagnild \& Young (1993) as "a personality characteristic that moderates the negative effects of stress and promotes adaptation" and by Smith \& Carlson (1997) in terms of "the ability to restore or maintain internal or external equilibrium under significant threat by means of human activities including thought and action". In addition, as reported by Gilligan (2001), resilience is more usefully considered as a variable quality that derives from a process of repeated interactions between individual and favorable features of the surrounding context in everyday life; the degree of resilience showed by individuals in a certain context can be related to the extent to which that context has elements that cultivate this resilience.

According to the model proposed by Hurtes \& Allen (2001), it is possible to mark out a typical resilient profile characterized by specific psychological dimensions: the "insight", that is the ability to understand people, situations and their communication; the "independence", consisting in the attitude to care for others while remaining true to own self; the "creativity" that allows to cope daily challenges through the generation of alternative solutions; the "sense of humor", referring to ability to poke fun themselves and to find joy in own context; the "initiative", that is, a desire to pursue proactively own life; the "supportive relationships", in terms of the ability to establish positive relationships with the others; and, finally, the "values orientation" that allows to identify the morally right and appropriate behavior. However, the main aspect of resilience is represented by the disposition to change, understood as the ability to re-establish a new equilibrium form, not pathological, but as a result of an adverse event. In relation to this topic, Achour \& Nor (2014) examined the role of resilience and social support as coping strategy in reducing depression and increasing student's life satisfaction, showing that resilience and social support were positively related to life satisfaction and that resilience was positively and significantly related with social support coping. In addition, Abolghasemi \& Taklavi Varaniyab (2010) studied how the relationship between resilience and perceived stress can influence life satisfaction in a sample of Iranian adolescents, showing that resilience and perceived positive stress are positively related to life satisfaction. Recently, De Caroli \& Sagone (2016) deepened the differences between the affective profiles in the dimensions of resilience and psychological well-being factors in Italian adolescents, underlining that adolescents with self-fulfilling profile reported higher resilience (sense of humor, competence, adaptability, and engagement) and psychological well-being (autonomy, purpose in life, and self-acceptance) than adolescents with the other affective profiles. 
In this direction the perception of personal self-efficacy, shown by each individual, influences the choices and efforts made in order to achieve established goal and can be improved by specific social experiences and learning processes, by means of the consciousness of personal limits and possibilities. Self-efficacy is directly linked to resilience and psychological well-being. So, De Caroli \& Sagone (2014a) analyzed the relationship between generalized self-efficacy and psychological well-being in a sample of highly and lowly efficient Italian adolescents, showing a significant and positive relationship between self-efficacy and environmental mastery, personal growth, and self-acceptance. As underlined by Bandura (1998), self-efficacy is represented by "beliefs in one's capabilities to organize and execute the courses of action required to produce given levels of attainments". According to this perspective, it affects the personal behaviors and environments with which the individual interacts and, in turn, is influenced by personal actions and environmental conditions. These perceived self-efficacy beliefs are referred to specific domains of the individual's psychological and social functioning; among these specific domains, it is possible to analyze the perceived self-efficacy in various spheres of life, underlining the importance of the same in order to guarantee the adequate development of the individual, such as, for example, the perceived interpersonal and problem solving self-efficacy defined as the ability to establish good relationships with other people or to find creative solutions to problems. Accordingly, Caprara, Gerbino, \& Delle Fratte (2001) proposed the perceived self-efficacy in the expression of positive emotions and the managing of negative ones, in terms of the individual's ability to efficiently express and manage his/her emotions. Additionally, Pastorelli, Vecchio, \& Boda (2001) studied the perceived self-efficacy in interpersonal and social communication, relating to the individual's skill to efficiently communicate with the others, to actively participate in group setting, and to assert own rights and opinions, and the perceived self-efficacy in problem solving, consisting of the ability to creatively solve problems and to find innovative solutions. These abilities fall into the general framework of life skills defined as "abilities for adaptive and positive behavior that enable individuals to deal efficiently with the demands and challenges of everyday life" (World Health Organization, 2003). In detail, life skills are psychosocial and interpersonal competencies that help people making informed decisions (decision making), solving problems (problem solving), thinking critically and creatively (critical and creative thinking), communicating efficiently (efficacy communication), building healthy relationships (interpersonal relationships), get involved with others (empathy), knowing themselves, recognizing feelings as it occur and discriminating between them (self-awareness), and, finally, managing emotions and stress. Life skills may be directed toward personal actions or the others, as well as toward actions to change the surrounding environment.

The rationale of this present study is given by double reasons: a) the reduced amount of researches focused on the relationship among positive affect, resi- 
lience, and self-efficacy in life skills during the adolescence; and b) the necessity to study the effects of positive growing factors in life span of adolescents.

\section{Method}

\subsection{Purpose of Study}

The main objective of this study was to investigate how positive affect can be in relation to the dimensions of resilience and perceived self-efficacy in life skills in a sample of Italian adolescents. We have hypothesized that:

$\mathrm{H}_{1}$ ) adolescents with high positive affect would report higher levels of perceived self-efficacy in life skills than those with low positive affect;

$\mathrm{H}_{2}$ ) adolescents with high positive affect would report higher levels of resilience than those with low positive affect.

Differences for sex and class groups in relation to positive affect, dimensions of resilience, and perceived self-efficacy in life skills will be analyzed.

\subsection{Participants}

The sample consisted of 147 Italian healthy adolescents ( $\mathrm{n}=60$ boys; $\mathrm{n}=87$ girls), randomly recruited from the third $(\mathrm{n}=46)$, fourth $(\mathrm{n}=59)$ and fifth $(\mathrm{n}=$ 42) classes of High State Schools sited in Catania (Eastern Sicily), Italy. Their age range was from 15 to 19 years $(M=17.3)$. Parental consent for the underage adolescents' participation to this study was requested and obtained in accordance with the requirements of privacy and anonymity laid down by Italian Law (Law Decree DL. 196/2003).

\subsection{Measure and Procedure}

For data collection we used a self-report and anonymous questionnaire for socio-demographic information and the following scales: the Positive and Negative Affect Schedule (PANAS; Watson et al., 1988; Terracciano, McCrae, \& Costa, 2003), the Resiliency Attitudes and Skills Profile (RASP; De Caroli \& Sagone, 2014b), and the Perceived Self-Efficacy Scales in Life Skills (Caprara, 2001; Pastorelli et al., 2001). The questionnaire was administered in a group setting during the school activities.

The Positive Affect and Negative Affect Schedule (Watson et al., 1988; Terracciano et al., 2003) assessed the affective components of subjective well-being by requiring participants to indicate on a 5 -point Likert scale to what extent $(1=$ very slightly, $5=$ extremely) they generally experienced 20 adjectives describing affective states ( 10 for positive affect and 10 for negative affect) during a specific period ("in this moment, today, last week, last month, or generally"). The positive affect scale includes adjectives such as "strong, proud, and interested"; the negative affect scale includes adjectives such as "afraid, ashamed, and nervous". The internal consistency of Italian PANAS, using the Cronbach's alpha coefficient, was satisfactory for positive affect scale $(\alpha=0.74)$ and negative affect scale $(\alpha=0.79)$. 
The Italian version of Resiliency Attitudes and Skills Profile (RASP: Hurtes \& Allen, 2001; De Caroli \& Sagone, 2014b) was a self-report scale formed by 30 items, valuable on a 6-point Likert scale from 1 (corresponding to "strongly disagree") to 6 intervals (corresponding to "strongly agree") and grouped into five dimensions of resilient profile: "adaptability" (consisting of 7 items, e.g., "I can change my surroundings", "When something goes wrong, I can tell if it was my fault"), "sense of humor" ( 3 items, e.g., "My sense of humor makes it easier to deal with tough situations", "Laughter helps me deal with stress"), "engagement" (7 items, e.g., "I can tell what mood someone is in just by looking at him/her", "My friend know they can count on me"), "control" (6 items, e.g., "I avoid situation where I could get into trouble", "I avoid people who could get me into trouble") and "competence" (5 items, e.g., "I say "no" to things I don't want to do", "It's ok if some people do not like me"). The internal consistency of Italian RASP, using the Cronbach's alpha coefficient, was satisfactory for total scale $(\alpha=$ $0.83)$.

The Perceived Self-Efficacy Scales in Life Skills were divided in four subscales (PSES_PE; PSES_NE: Caprara et al., 2001; PSES_PS; PSES_IC/SC: Pastorelli et al., 2001), respectively used to analyze: 1-2) the ability to regulate and manage the expression of positive (PSES_PE: constituted by 7 items, e.g., "I can feel gratified over achieving what I set out to do") and negative emotions (PSES_NE: constituted by 8 statements, e.g., "I can get over irritation quickly for wrongs I have experienced"); 3) the ability to communicate in interpersonal and social relations (PSES_IC/SC: composed by 19 items, e.g., "How much do you think to be able to avoid heated disputes during a meeting?"); and 4) the ability to respond in problem-solving situations in efficient way (PSES_PS: constituted by 14 statements, e.g., "How much do you think to be able to recognize alternative and positive solutions for problems?"). Participants were asked to indicate how much they felt themselves able in a range between 1 (equal to "not at all efficient") and 7 intervals (equal to "completely efficient"). The internal consistency of Perceived Self-Efficacy Scales in Life Skills, using the Cronbach's alpha coefficient, was satisfactory for each subscales (PSES_PE: $\alpha=0.82$; PSES_NE: $\alpha=0.86$; PSES_IC/SC: $\alpha=0.85$; PSES_PS: $\alpha=0.84$ ).

\subsection{Statistical Analysis}

The examination of the statistical significance of results was carried out using the SPSS 20 software (Statistical Package for Social Sciences) by means of the following tests: t-Student, One-Way ANOVA, linear correlations and regressions. Class groups and sex were used as independent variables while mean scores on positive affect, dimensions of resilience, and perceived self-efficacy in life skills were used as dependent variables.

\section{Results}

Descriptive analyses for RASP showed that total sample of adolescents obtained 
high mean scores in competence $(\mathrm{M}=4.93$, sd $=0.71)$ and engagement $(\mathrm{M}=$ 4.84 , sd $=0.59)$, intermediate mean scores in control $(M=4.75$, $s d=0.65)$, and low mean scores in adaptability $(\mathrm{M}=4.35, \mathrm{sd}=0.69)$ and sense of humor $(\mathrm{M}=$ 4.54, sd = 1.11). Positive and statistically significant linear correlations among dimensions of resilience were found: so, sense of humor was positively correlated with competence $(r=0.26, p=0.001)$, adaptability $(r=0.33, p<0.001)$, and engagement $(r=.25, p=.002)$; competence was positively correlated with adaptability $(r=0.39, p<0.001)$, control $(r=0.25, p=0.002)$, and engagement $(r=0.32, p<0.001)$; adaptability was positively correlated with control $(r=0.42$, $p<0.001)$ and engagement $(r=0.51, p<0.001)$; finally, control was positively correlated with engagement $(r=0.26, p=0.002)$.

Differences for sex in dimensions of resilience were noted only in the sense of humor $\left(t_{(146)}=2.814, p=0.006\right)$ : so, boys obtained higher levels of humor $(\mathrm{M}=4.84$, $\mathrm{sd}=0.97)$ than girls $(\mathrm{M}=4.34, \mathrm{sd}=1.16)$. Differences for classes in dimensions of resilience were found in competence $\left(F_{(2,144)}=3.595, p=0.030\right)$ and adaptability $\left(F_{(2,144)}=3.617, p=0.029\right)$ (see Table 1$)$ : so, it is possible to note a curvilinear trend in these two dimensions (for competence: third classes $M=4.88, \mathrm{sd}=0.81$; fourth classes $M=5.11$, sd $=0.62$; fifth classes $M=4.74$, $\mathrm{sd}=0.67$; for adaptability: third classes $M=4.36$, sd $=0.74$; fourth classes $M=4.50$, sd $=0.65$; fifth classes $M=4.13$, sd = 0.68). Post-hoc t-tests with Bonferroni's correction confirmed that there were significant differences in relation to competence (for $p=$ 0.029 ) and adaptability (for $p=0.029$ ) between fourth and fifth classes.

Table 1. Descriptive analyses for RASP: differences for classes.

\begin{tabular}{|c|c|c|c|}
\hline \multirow{2}{*}{ RASP dimensions } & \multicolumn{3}{|c|}{ Differences for classes } \\
\hline & Classes & Mean & Std. deviation \\
\hline \multirow{3}{*}{ Sense of humor } & III & 4.53 & 1.21 \\
\hline & IV & 4.76 & 0.94 \\
\hline & $\mathrm{V}$ & 4.24 & 1.17 \\
\hline \multirow{3}{*}{ Competence } & III & 4.88 & 0.82 \\
\hline & IV & 5.11 & 0.61 \\
\hline & $\mathrm{V}$ & 4.74 & 0.67 \\
\hline \multirow{3}{*}{ Adaptability } & III & 4.36 & 0.73 \\
\hline & IV & 4.50 & 0.65 \\
\hline & $\mathrm{V}$ & 4.13 & 0.68 \\
\hline \multirow{3}{*}{ Control } & III & 4.43 & 0.88 \\
\hline & IV & 4.75 & 0.67 \\
\hline & $\mathrm{V}$ & 4.59 & 0.81 \\
\hline \multirow{3}{*}{ Engagement } & III & 4.89 & 0.60 \\
\hline & IV & 4.86 & 0.57 \\
\hline & $\mathrm{V}$ & 4.75 & 0.60 \\
\hline
\end{tabular}


Descriptive analyses for PANAS indicated that total sample of adolescents obtained higher mean scores in positive affect $(M=35.27$, sd $=5.74)$ than in negative affect $(\mathrm{M}=25.32, \mathrm{sd}=6.81)\left(t_{(146)}=12.95, p<0.001\right)$, without significant differences for classes. On the contrary, in relation to sex differences, results showed that boys reached higher mean scores than girls only in positive affect $\left(t_{(146)}=2.25, p=0.026\right)$ (Table 2).

With reference to the perceived self-efficacy in life skills, descriptive analyses indicated that total sample of adolescents obtained high mean scores in PSES_IC/SC $(M=98.05$, sd $=13.6)$ and PSES_PS $(M=71.31$, sd = 11.04 $)$, and low mean scores in PSES_NE $(M=58.89$, sd = 1.7) and PSES_PE $(M=40.91$, sd =6.7), without significant differences for classes. Positive and statistically significant linear correlations among measures of perceived self-efficacy in life skills were found: so, PSES_PS was strongly related to PSES_IC/SC $(r=0.66, p<$ $0.001)$, PSES_NE $(r=0.58, p<0.001)$, and PSES_PE $(r=0.42, p<0.001)$; PSES_IC/SC was strongly related both to PSES_NE $(r=0.55, p<0.001)$ and PSES_PE $(r=0.54, p<0.001)$; finally, PSES_NE was strongly related to PSES_PE $(r=0.54, p<0.001)$.

Also in this case, differences for sex (see Table 3 ) in perceived self-efficacy in life skills were noted only for self-efficacy in regulation of positive emotions (PSES_PE: $t_{(146)}=-1.967, p=0.048$ ) and managing of negative emotions (PSES_ $\left.\mathrm{NE}: t_{(146)}=2.824, p=0.005\right)$ : so, boys reached higher mean scores on self-efficacy

Table 2. Descriptive analyses for PANAS: differences for sex.

\begin{tabular}{cccc}
\hline \multirow{2}{*}{ PANAS } & \multicolumn{3}{c}{ Differences for sex } \\
\cline { 2 - 4 } & Sex & Mean & Std. deviation \\
\hline \multirow{2}{*}{ Positive affect } & Boys & 36.52 & 5.20 \\
& Girls & 34.42 & 5.92 \\
Negative affect & Boys & 25.06 & 4.35 \\
& Girls & 24.92 & 4.38 \\
\hline
\end{tabular}

Table 3. Descriptive analyses for self-efficacy in life skills: differences for sex.

\begin{tabular}{cccc}
\hline \multirow{2}{*}{ Life skills } & \multicolumn{3}{c}{ Differences for sex } \\
\cline { 2 - 4 } & Sex & Mean & Std. deviation \\
\hline \multirow{2}{*}{ PSES_PS } & Boys & 72.88 & 10.60 \\
& Girls & 70.23 & 11.26 \\
PSES_IC/SC & Boys & 99.41 & 12.19 \\
& Girls & 97.10 & 14.54 \\
PSES_NE & Boys & 62.60 & 12.76 \\
& Girls & 56.34 & 13.80 \\
PSES_PE & Boys & 39.61 & 6.64 \\
& Girls & 41.80 & 6.59 \\
\hline
\end{tabular}


in managing of negative emotions than girls, while girls obtained higher mean scores on self-efficacy in regulation of positive emotions than boys. These results confirmed the findings obtained by Caprara et al. (2006) in relation to the sex differences about the perceived self-efficacy in the regulation and managing of positive and negative emotions.

Analyzing linear correlations between positive affect and each subscale of perceived self-efficacy in life skills (Table 4), results showed that: positive affect was positively correlated with perceived self-efficacy in problem solving (PSES_PS), in interpersonal and social communication (PSES_IC/SC), in managing of negative emotions (PSES_NE), and in regulation of positive emotions (PSES_PE). According to $\mathrm{H}_{1}$ ), the deepening carried out with linear regression analysis demonstrated that positive affect influenced PSES_PS $(\beta=0.401, t=5.27, p<0.001)$, PSES_IC/SC $(\beta=0.324, t=4.13, p<0.001)$, PSES_NE $(\beta=0.300, t=3.78, p<$ $0.001)$, and PSES_PE $(\beta=0.283, t=3.55, p=0.001)$. These results confirmed that adolescents with high positive affect reported high levels of perceived self-efficacy in life skills.

Proceeding to linear correlations between positive affect and each dimension of resilience (Table 5), results demonstrated that: positive affect was positively and moderately correlated with adaptability, but weakly with engagement, control, and sense of humor. According to $\mathrm{H}_{2}$ ), the deepening carried out with linear regression analysis demonstrated that positive affect influenced adaptability $(\beta=0.397, t=5.21, p<0.001)$, control $(\beta=0.205, t=2.53, p=0.013)$, and engagement $(\beta=0.321, t=4.09, p<0.001)$, and sense of humor $(\beta=0.188, t=$ 2.30, $p=0.023$ ). Also in this case, these evidences confirmed that adolescents with high positive affect reported high levels of resilience.

\section{Discussion}

According to initial expectations, the findings of the current study revealed that $\left(\mathrm{H}_{1}\right)$ adolescents with high positive affect reported higher levels of perceived self-efficacy in life skills than those with low positive affect; this result meant that

Table 4. Linear correlations between positive affect and self-efficacy in life skills.

\begin{tabular}{ccc}
\hline \multirow{2}{*}{ Life skills } & \multicolumn{3}{c}{ Positive affect } \\
\cline { 2 - 3 } & Pearson's r & Value \\
\hline PSES_PS & $\mathrm{R}$ & 0.34 \\
& Sig. & 0.000 \\
PSES_IC/SC & $\mathrm{R}$ & 0.23 \\
& Sig. & 0.005 \\
PSES_NE & $\mathrm{R}$ & 0.23 \\
& Sig. & 0.005 \\
PSES_PE & $\mathrm{R}$ & 0.24 \\
& Sig. & 0.003 \\
\hline
\end{tabular}


Table 5. Linear correlations between positive affect and dimensions of resilience.

\begin{tabular}{ccc}
\hline \multirow{2}{*}{ RASP dimensions } & \multicolumn{2}{c}{ Positive affect } \\
\cline { 2 - 3 } & Pearson's r & Value \\
\hline Sense of humor & $\mathrm{R}$ & 0.21 \\
& Sig. & 0.010 \\
Competence & $\mathrm{R}$ & 0.14 \\
& Sig. & 0.098 \\
Adaptability & $\mathrm{R}$ & 0.35 \\
& Sig. & 0.000 \\
Control & $\mathrm{R}$ & 0.17 \\
& Sig. & 0.042 \\
Engagement & $\mathrm{R}$ & 0.27 \\
& Sig. & 0.001 \\
\hline
\end{tabular}

adolescents that feel enthusiastic, active, alert, and characterized by a state of high energy, full concentration, and pleasurable engagement, perceived themselves as highly able to creatively solve problems and find innovative solutions, to efficiently express the positive emotions and to manage the negative ones, and, finally, to efficiently communicate with the others, to actively participate in group setting, and to assert own rights and ideas. Furthermore, in relation to $\mathrm{H}_{2}$, adolescents with high positive affect reached higher levels of resilience than those with low positive affect in terms of adaptability and engagement; so, it meant that these adolescents showing to be enthusiastic, active and alert, started up an high inclination to adapt themselves to their surrounding and to cope with adversities in daily life (as typical aspect recognized in resilient profile). These findings are in line with the evidences provided by Tugade \& Fredrickson (2004) and Ong et al. (2006) with reference to the association between positive affect and resilience; so, positive affect is positively (but partially) related with high resilience. In the present study, adolescents with high positive affect achieved high mean scores in two of the dimensions of resilience (that is, adaptability and, moderately, engagement).

About the relevant differences for sex (but not for classes), results were in line with the previous findings provided by research of De Caroli \& Sagone (2016), according to which boys tended to bounce back adversities using humor more than girls; with the findings observed by Schütz et al. (2013) and by Schütz, Garcia, \& Archer (2014), according to which girls expressed higher levels of negative affect than boys; and, with the evidences of Caprara et al. (2006) in the superiority of boys for managing of negative emotions compared to girls in terms of perceived self-efficacy.

The importance of this study can be due to the attention to the reduced amount of investigations focused on the relationship among affect states, resilience, and perceived self-efficacy in life skills in Italian healthy adolescents, and 
to the suitability to deepen the effects of positive growing factors such as "positive affectivity" in the life span of adolescents. Additionally, the findings of the current study permitted to think about the role of educational programs based on the development of life skills, demonstrated as widely efficient in various areas of well-being promotion in adolescence, including positive affectivity and resilience as protective factors in different way for boys and girls. In this direction, some recent studies investigated that children and adolescents who attended educational programs focused on the promotion of self-efficacy in life skills reduced the onset of at-risk and maladaptive behaviors (Griffin et al., 2003; Botvin \& Griffin, 2004; Yankah \& Aggleton, 2008; Menrath et al., 2012; Jegannathan, Dahlblom, \& Kullgren, 2014): it was possible to observe a significant and positive effect for the reduction of health-risk behaviors in the intervention group, compared to control group (see Menrath et al., 2012), confirming the efficacy of school-based on life skills programs. Furthermore, more recently, King et al. (2016) adopted the life skills programs for adolescents with physical disabilities and Gates, Kang, \& Lerner (2017) for adolescents with autism spectrum disorders, confirming that these programs provided favorable and encouraging circumstances for experiences concerning the enrichment of social interactions, sense of autonomy, personal growth, and social competence. These aspects are directly and strictly associated with the promotion of psychological well-being and resilience during the adolescence. Finally, further positive results were obtained by Srikala \& Kishore Kumar (2010) about the application of these life skills educational programs in the promotion of adaptation at school, success, and self-esteem: so, adolescents significantly increased their levels of self-esteem, adopted more adequately coping strategies, were engaged more frequently in prosocial behaviors, and developed positive interactions with teachers at school.

\section{Limits}

Among the limits of the present study, it is possible to point out the necessity: 1) to replicate this investigation with a large number of Italian healthy adolescents for the representativeness of the sample; 2) to adopt the double analysis both for positive and negative affect, considering that literature review seems to indicate these two aspects as separate but equally important variables; and, finally, 3) to carry out a longitudinal study, from early adolescence to young adulthood, in order to emphasize the change in these aspects of youth development.

\section{Conclusion}

Given the influence of positive affect both on resilience and perceived self-efficacy in life skills and the significance of educational programs focused on the increasing of self-efficacy in life skills, future investigations could better understand the functioning of "protective factors" actively involved in the transition from childhood to adolescence, in line with the flourishing approach developed by Positive Psychology (Seligman, 2011) in supporting the promotion of psy- 
chological well-being and the increasing of individual's bio-psycho-social skills.

\section{References}

Abolghasemi, A., \& Taklavi Varaniyab, S. (2010). Resilience and Perceived Stress: Predictors of Life Satisfaction in Students of Success and Failure. Procedia-Social and Behavioral Sciences, 5, 748-752. https://doi.org/10.1016/j.sbspro.2010.07.178

Achour, M., \& Nor, M. R. M. (2014). The Effects of Social Support and Resilience on Life Satisfaction of Secondary School Students. Journal of Academic and Applied Studies, 4, 12-20.

Archer, T., Adolfsson B., \& Karlsson, E. (2008). Affective Personality as Cognitive-Emotional Pre-Symptom Profiles Regulatory for Self-Reported Health Predispositions. Neurotoxicity Research, 14, 21-44. https://doi.org/10.1007/BF03033573

Bandura, A. (1998). Health Promotion from the Perspective of Social Cognitive Theory. Psychology and Health, 13, 623-649. https://doi.org/10.1080/08870449808407422

Botvin, G. J., \& Griffin, K. W. (2004). Life Skills Training: Empirical Findings and Future Directions. Journal of Primary Prevention, 25, 211-232. https://doi.org/10.1023/B:JOPP.0000042391.58573.5b

Caprara, G. V., Gerbino, M., \& Delle Fratte A. (2001). Autoefficacia Interpersonale. In G. V. Caprara (Ed.), La valutazione dell'autoefficacia. Costrutti e strumenti [Self-Efficacy Measurement. Theories and Measures.] (pp. 51-62). Trento: Erickson.

Caprara, G. V., Steca, P., Gerbino, M., Paciello, M., \& Vecchio, G. M. (2006). Looking for Adolescents' Well-being: Self-Efficacy Beliefs as Determinants of Positive Thinking and Happiness. Epidemiology and Psychiatric Sciences, 15, 30-43.

https://doi.org/10.1017/S1121189X00002013

Caprara, G. V. (2001). La valutazione dell'autoefficacia. [Self-Efficacy Measurement.] Trento: Erickson.

De Caroli, M. E., \& Sagone, E. (2016). Resilience and Psychological Well-being: Differences for Affective Profiles in Italian Middle and Late Adolescents. Revista INFAD de Psicología, 1, 149-160.

De Caroli, M. E., \& Sagone, E. (2014a). Generalized Self-Efficacy and Well-Being in Adolescents with High vs. Low Scholastic Self-efficacy. Procedia-Social and Behavioral Sciences, 141, 867-874. https://doi.org/10.1016/j.sbspro.2014.05.152

De Caroli, M. E., \& Sagone, E. (2014b). Resilient Profile and Creative Personality in Middle and Late Adolescents: A Validation Study of the Italian-RASP. American Journal of Applied Psychology, 2, 53-58.

Di Fabio, A., \& Bucci, O. (2015). Affective Profiles in Italian High School Students: Life Satisfaction, Psychological Well-being, Self-esteem, and Optimism. Frontiers in Psychology, 6, 1-6. https://doi.org/10.3389/fpsyg.2015.01310

Garcia, D. (2012). The Affective Temperaments: Differences between Adolescents in the Big Five Model, and Cloninger's Psychobiological Model of Personality. Journal of Happiness Studies, 13, 999-1017. https://doi.org/10.1007/s10902-011-9303-5

Garcia, D., \& Moradi, S. (2013). The Affective Temperaments and Well-being: Swedish and Iranian Adolescents' Life Satisfaction and Psychological Well-being. Journal of Happiness Studies, 14, 689-707. https://doi.org/10.1007/s10902-012-9349-Z

Garcia, D., \& Siddiqui, A. (2009). Adolescents' Affective Temperaments: Life Satisfaction, Interpretation and Memory of Events. The Journal of Positive Psychology, 4, 155-167. https://doi.org/10.1080/17439760802399349 
Garcia, D., Sagone, E., De Caroli, M. E., \& Al Nima, A. (2017). Italian and Swedish Adolescents: Differences and Associations in Subjective Well-Being and Psychological Well-being. PeerJ, 5, 1-14. https://doi.org/10.7717/peerj.2868

Gates, J. A., Kang, E., \& Lerner, M. D. (2017). Efficacy of Group Social Skills Interventions for Youth with Autism Spectrum Disorder: A Systematic Review and Meta-Analysis. Clinical Psychology Review, 52, 164-181. https://doi.org/10.1016/j.cpr.2017.01.006

Gilligan, R. (2001). Promoting Resilience: A Resource Guide on Working with Children in the Care System. London: British Agencies for Adoption and Fostering.

Griffin, K. W., Botvin, G. J., Nichols, T. R., \& Doyle, M. M. (2003). Effectiveness of a Universal Drug Abuse Prevention Approach for Youth at High Risk for Substance Use Initiation. Preventive Medicine, 36, 1-7. https://doi.org/10.1006/pmed.2002.1133

Hurtes, K. P., \& Allen L. R. (2001). Measuring Resiliency in Youth: The Resiliency Attitudes Skills Profile. Therapeutic Recreation Journal, 35, 333-347.

Jegannathan, B., Dahlblom, K., \& Kullgren, G. (2014). Outcome of a School-Based Intervention to Promote Life-Skills among Young People in Cambodia. Asian Journal of Psychiatry, 9, 78-84. https://doi.org/10.1016/j.ajp.2014.01.011

King, G., Kingsnorth, S., McPherson, A., Jones-Galley, K., Pinto, M. et al. (2016). Residential Immersive Life Skills Programs for Youth with Physical Disabilities: A Pilot Study of Program Opportunities, Intervention Strategies, and Youth Experiences. Research in Developmental Disabilities, 55, 242-255.

https://doi.org/10.1016/j.ridd.2016.04.014

Luthar, S. S., \& Cicchetti, D. (2000). The Construct of Resilience: Implications for Interventions and Social Policies. Development and Psychopathology, 12, 857-885. https://doi.org/10.1017/S0954579400004156

Menrath, I., Müller-Godeffroy, E., Prüssmann, C., \& Thyen, U. (2012). Evaluation of School-Based Life Skills Programs in a High-Risk Sample: A Controlled Longitudinal Multi-Centre Study. Journal of Public Health, 20, 159-170. https://doi.org/10.1007/s10389-011-0468-5

Norlander, T., Johansson, A., \& Bood, S. A. (2005). The Affective Personality: Its Relation to Quality of Sleep, Well-Being and Stress. Social Behavior and Personality, 33, 709-722. https://doi.org/10.2224/sbp.2005.33.7.709

Ong, A. D., Bergeman, C. S., Bisconti, T. L., \& Wallace, K. A. (2006). Psychological Resilience, Positive Emotions, and Successful Adaptation to Stress in Later Life. Journal of Personality and Social Psychology, 91, 730-749.

https://doi.org/10.1037/0022-3514.91.4.730

Pastorelli, C., Vecchio, G. M., \& Boda, G. (2001). Autoefficacia Nelle Life Skills: Soluzione dei problemi e comunicazione interpersonale. [Life Skills Self-Efficacy: Problem Solving and Interpersonal Communication.] In G. V. Caprara (Ed.), La valutazione dell'autoefficacia. Costrutti e strumenti (pp. 137-146). Trento: Erickson.

Ryff, C. D. (2014). Psychological Well-Being Revisited: Advances in the Science and Practice of Eudaimonia. Psychotherapy and Psychosomatics, 83, 10-28.

https://doi.org/10.1159/000353263

Schütz, E., Garcia, D., \& Archer, T. (2014). Affective State, Stress, and Type A-Personality as a Function of Gender and Affective Profiles. International Journal of Research Studies in Psychology, 3, 51-64. https://doi.org/10.5861/ijrsp.2013.450

Schütz, E., Sailer, U., Al Nima, A., Rosenberg, P. et al. (2013). The Affective Profiles in the USA: Happiness, Depression, Life Satisfaction, and Happiness-Increasing Strategies. 
PeerJ, 1, e156. https://doi.org/10.7717/peerj.156

Seligman, M. (2011). Flourish. A Visionary New Understanding of Happiness and Well-Being. New York, NY: Simon \& Schuster.

Smith, C., \& Carlson, B. E. (1997). Stress, Coping, and Resilience in Children and Youth. Social Service Review, 71, 231-256. https://doi.org/10.1086/604249

Srikala, B., \& Kishore Kumar, K. V. (2010). Empowering Adolescents with Life Skills Education in Schools-School Mental Health Program: Does It Work? Indian Journal of Psychiatry, 52, 344-349. https://doi.org/10.4103/0019-5545.74310

Tellegen, A., Watson, D., \& Clark, L. A. (1999). On the Dimensional and Hierarchical Structure of Affect. Psychological Science, 10, 297-303. https://doi.org/10.1111/1467-9280.00157

Terracciano, A., McCrae, R. R., \& Costa, P. T. Jr. (2003). Factorial and Construct Validity of the Italian Positive and Negative Affect Schedule (PANAS). European Journal of Psychological Assessment, 19, 131-141. https://doi.org/10.1027//1015-5759.19.2.131

Tugade, M. M., \& Fredrickson, B. L. (2004). Resilient Individuals Use Positive Emotions to Bounce Back from Negative Emotional Experiences. Journal of Personality and Social Psychology, 86, 320-333. https://doi.org/10.1037/0022-3514.86.2.320

Wagnild, G. M., \& Young, H. M. (1993). Development and Psychometric Evaluation of the Resilience Scale. Journal of Nursing Measurement, 1, 165-178.

Watson, D., \& Tellegen, A. (1985). Toward a Consensual Structure of Mood. Psychological Bulletin, 98, 219-235. https://doi.org/10.1037/0033-2909.98.2.219

Watson, D., Clark, L. A., \& Tellegen, A. (1988). Development and Validation of Brief Measures of Positive and Negative Affect: The PANAS Scales. Journal of Personality and Social Psychology, 54, 1063-1070. https://doi.org/10.1037/0022-3514.54.6.1063

World Health Organization (2003). Skills for Health, Information Series on School Health. Document Number 9.

Yankah, E., \& Aggleton, P. (2008). Effects and Effectiveness of Life Skills Education for HIV Prevention in Young People. AIDS Education \& Prevention, 20, 465-485.

https://doi.org/10.1521/aeap.2008.20.6.465 